\title{
Conceptual Numerical Modeling of Large-Scale Footwall Behavior at the Kiirunavaara Mine, and Implications for Deformation Monitoring
}

\author{
M. Svartsjaern ${ }^{1}$ D. Saiang ${ }^{1}$ E. Nordlund ${ }^{1} \cdot$ A. Eitzenberger ${ }^{1}$
}

Received: 3 November 2014/ Accepted: 7 April 2015/Published online: 24 May 2015

(c) The Author(s) 2015. This article is published with open access at Springerlink.com

\begin{abstract}
Over the last 30 years, the Kiirunavaara mine has experienced a slow but progressive fracturing and movement in the footwall rock mass, which is directly related to the sublevel caving (SLC) method utilized by Luossavaara-Kiirunavaara Aktiebolag (LKAB). As part of an ongoing work, this paper focuses on describing and explaining a likely evolution path of large-scale fracturing in the Kiirunavaara footwall. The trace of this fracturing was based on a series of damage mapping campaigns carried out over the last 2 years, accompanied by numerical modeling. Data collected from the damage mapping between mine levels 320 and $907 \mathrm{~m}$ was used to create a 3D surface representing a conceptual boundary for the extent of the damaged volume. The extent boundary surface was used as the basis for calibrating conceptual numerical models created in UDEC. The mapping data, in combination with the numerical models, indicated a plausible evolution path of the footwall fracturing that was subsequently described. Between levels 320 and $740 \mathrm{~m}$, the extent of fracturing into the footwall appears to be controlled by natural pre-existing discontinuities, while below $740 \mathrm{~m}$, there are indications of a curved shear or step-path failure. The step-path is hypothesized to be activated by rock mass heave into the SLC zone above the current
\end{abstract}

M. Svartsjaern

mikael.svartsjaern@1tu.se

1 Division of Mining and Rock Engineering, Department of Civil, Environmental and Natural Resources Engineering, Luleå University of Technology, Luleå, Sweden extraction level. Above the $320 \mathrm{~m}$ level, the fracturing seems to intersect a subvertical structure that daylights in the old open pit slope. Identification of these probable damage mechanisms was an important step in order to determine the requirements for a monitoring system for tracking footwall damage. This paper describes the background work for the design of the system currently being installed.

Keywords Numerical modeling · Footwall behavior . Failure evolution · Case study

\section{Introduction}

Over the last 30 years, the Kiirunavaara mine has experienced a slow but progressive fracturing and movement in the footwall rock mass. This is directly related to the sublevel caving (SLC) method utilized by the mining company Luossavaara-Kiirunavaara Aktiebolag (LKAB). SLC is a cost-effective mass-mining method, which allows for a high level of automation but inherently causes the host rock, particularly on the hangingwall side, to cave progressively and fill the voids from ore extraction. This progressive caving is a prerequisite for optimal performance of the operation. As mining progresses, the footwall contact becomes de-stressed and assumes a slope-like geometry. The footwall "slope" is partially supported by the caved rock masses from the hangingwall (Villegas and Nordlund 2008). Despite this, damage on the footwall crest as well as within the footwall rock mass has been observed since the late 1980s.

It is essential to accurately forecast the global stability of the footwall with increasing mining depth for the continued operation of the mine, as well as the design of the infrastructure located both within the footwall and on the 
ground surface. Even though most of the production-critical infrastructure (skip shafts, crushers, etc.) is located at a considerable distance from the ore contact, a large-scale movement or failure in the footwall could drastically impede mining operations. It was, therefore, considered important to carry out early or timely prognoses to identify any potential associated risks.

Progressive failure of the footwall at the Kiirunavaara mine has been studied by a number of authors (e.g., Singh et al. 1993; Lupo 1996; Sjöberg 1999). These studies were aimed at identifying the mechanisms driving the potentially progressive footwall failure. Singh et al. (1993) identified tensile mechanisms as the source of the failure. However, Lupo (1996) and Sjöberg (1999) showed that the observed damage did not fit well with patterns associated with the proposed tensile mechanisms. Villegas and Nordlund (2008) showed that the caved material supports the footwall even during draw, thus contradicting some of the findings of Lupo (1996), where increased shear development during draw was indicated. Villegas and Nordlund (2008) showed that the shear-traction from the caved material on the footwall induced only local failures on the footwall face close to the undercut level. These local failures did not progress significantly into the wall. Sjöberg (1999) surmised circular shear failure as the primary failure mode. The potential for large-scale footwall instability was also modeled by Sitharam and Madhavi Latha (2002)using similar input as Lupo (1996), but with a calibration of the rock mass to include strength reduction due to jointing. According to Sitharam and Madhavi Latha (2002), the results from the model showed the development of shear bands that corresponded "fairly well" to the failure observations reported by Sjöberg (1999). In continuation to the above works, this paper presents a new study which was conducted in order to further the understanding of the footwall failure evolution as mining progresses deeper. The current study involved reviewing past works and performing new damage mapping campaigns to outline the damage extent, as well as pursuing numerical simulations to gain insight into the potential failure mechanisms driving the footwall instability. Conceptual numerical modeling was conducted in the form of parameter study and back analysis, where the results from the damage mapping presented by Nilsson et al. (2014) combined with additional damage mapping data from the current work were used as the basis for model calibration. The ultimate objective was to use the results from the mapping campaign and numerical study to design a monitoring system, which is currently being implemented, to track the indicated progression of large-scale footwall damage. This is in order to either re-affirm the failure mechanisms made plausible by this paper or provide a completely new understanding of the failure mechanisms involved in the footwall instability.

\section{Kiirunavaara Mine}

The Kiirunavaara mine, situated near the city of Kiruna in northern Sweden, is a large-scale iron ore SLC operation producing $28 \mathrm{Mt}$ (million metric tons) of crude ore per year. The mine is currently transitioning from a main haulage at level $1,045 \mathrm{~m}$ to a new at level $1,365 \mathrm{~m}$, situated at a depth of roughly $1,100 \mathrm{~m}$ (actual depth) from the ground surface. Originally, the ore was mined in an open pit, but the mine transferred to underground mining in the early 1960s.

\subsection{Mine Layout}

In general, the orientation of the mine is north to south, with the footwall on the west side and the hangingwall on the east. The orebody undercuts the hangingwall as it dips roughly $60^{\circ}$ east. The orientation and naming of objects and infrastructure is associated to a local 3D coordinate system, with the vertical $z$-axis originating at the premining summit of the Kiirunavaara mountain. The local $y$ axis is approximately oriented north to south and follows the general strike of the orebody, and the $x$-axis is oriented roughly west to east. The $z$-coordinates increase with depth, while the $y$-coordinates increase southwards and the $x$-coordinates increase eastwards into and beyond the hangingwall; see Fig. 1.

The mining-related surface and underground infrastructure is located on and within the footwall. The underground infrastructure is situated inside the footwall and aligned parallel to the strike of the orebody; see Fig. 2. The main infrastructure components in the mine (e.g., roads and ore passes) are designated by their placement according to the local $y$-coordinate, e.g., ore pass group 19 is located roughly at Y19. Most of the permanent infrastructure, such as crushers, skip shafts, and workshops, are located far into the footwall in the so-called CA-area. The CA-area is located between $y$-coordinates Y21 and Y25. From the CAarea, access and transportation drifts extend eastwards to the mining areas. The main orebody is sectioned into production blocks named by their position along the $y$ coordinate axis. Mining of these main ore blocks is currently performed between levels 935 and $1051 \mathrm{~m}$.

\subsection{Geology}

The main host rock type in the footwall is Precambrian aged trachyo-andesite (Henry and Dahnér-Lindqvist 2000). The trachyo-andesite is internally designated as syenite porphyry, which is subdivided into five categories with respect to the strength properties, denoted SP1-SP5. The different classes of porphyry are, to a large extent, intermixed in the 
Fig. 1 Perspective view of the Kiirunavaara mine open pit area with coordinate orientation

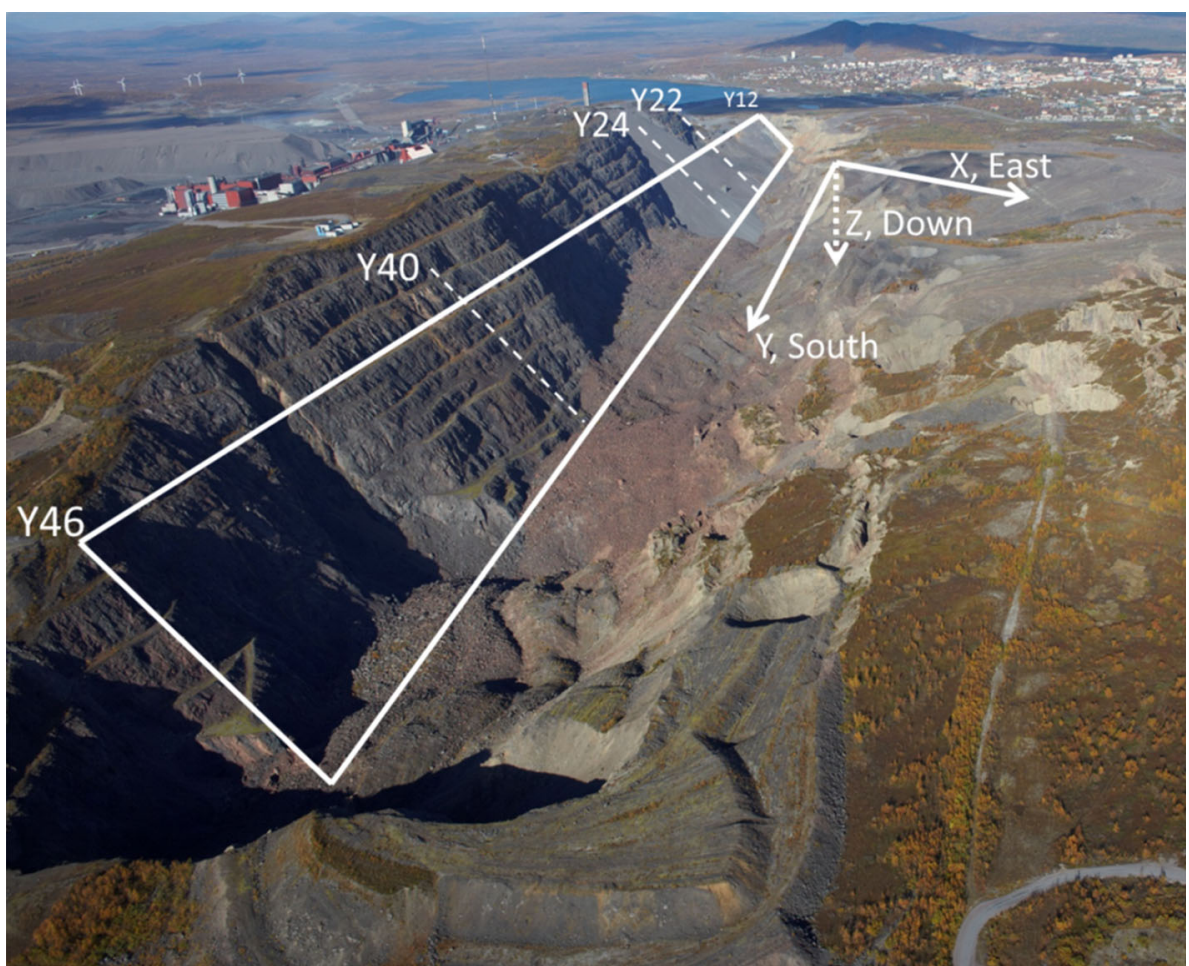

Fig. 2 Principal layout of the Kiirunavaara mine infrastructure (image courtesy of LKAB)

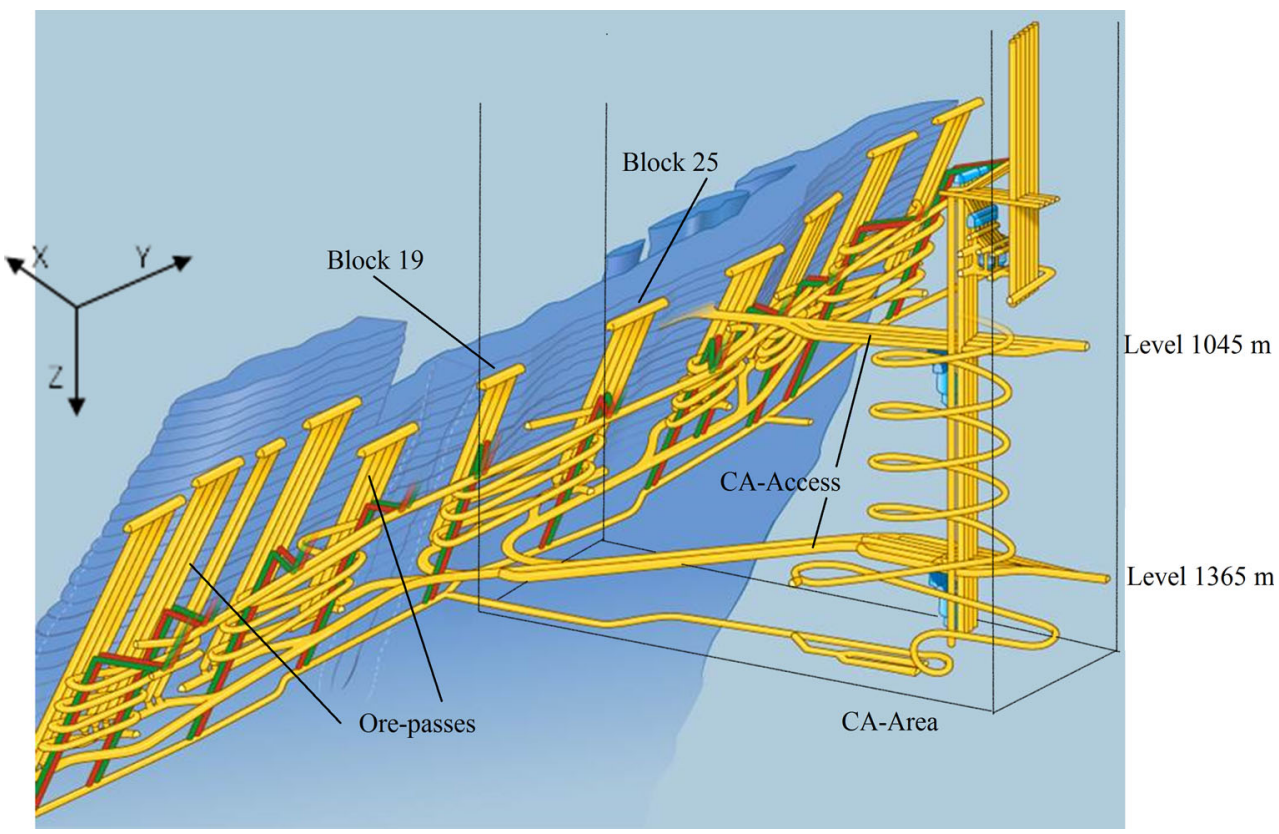

rock mass and are replaced by other rock types as one moves farther into the footwall, see e.g., Andersson (2009). The in situ rock mass rating, RMR, of the footwall rock mass has been investigated by several authors and was summarized to be in the range of $49-68$ by Sandström (2003). The intact rock strength was referenced by Sjöberg (1999) as varying between 140 and $300 \mathrm{MPa}$, depending on the porphyry type tested (i.e., SP1-SP5). At the footwall contact, the presence of 0.2-0.4-m-thick zones of amphibolite and actinolite skarns has been documented by, e.g., Lupo (1996). Sandström (2003) noted that the ore-footwall contact included breccia, consisting of actinolitic amphibole with an RMR of 22 . This contact was identified to be increasingly prominent in the north part of Kiirunavaara. 
The predominant joint orientation close to the production areas is the locally denoted "Kapten" orientation striking roughly WNW-ESE and dipping steeply to the south. A second dominant orientation becoming more common as the depth increases is SW-NE, which is dipping steeply NW. In addition to these sets, ore-parallel joints striking $\mathrm{N}-\mathrm{S}$ and dipping steeply to the east are common throughout the mine. In general, the joints do not cross the ore contact zone, even though the major orientations are roughly the same on both sides of the contact (Mattsson et al. 2010).

\section{Current Monitoring}

Field data are collected and separated in relation to ground surface and underground deformations. Currently, most of the active monitoring is performed on the ground surface and is, thus, mostly related to surface subsidence monitoring. Several systems have been utilized to monitor the rock mass movement in the footwall underground, on both local and global scales. However, all but one of these systems have fallen out of regular use. Only a seismic monitoring system constituting permanently installed geophones near the excavation level remains active.

\subsection{Surface and Underground Monitoring}

Surface cracks have been systematically mapped and tracked in varying regularity since 1992 . The mapping was first focused within the extent of the open pit area, but has later shifted to the northernmost parts of the footwall crest, where cracks have since been observed outside the open pit area. Aerial photographs by helicopter overflights exist from 2006 and have been captured yearly since 2008 .

Both the footwall and hangingwall are monitored by GPS along pre-set monitoring lines. The footwall monitoring lines include a total of 84 hubs, of which the majority are measured once a year. However, some specific points of special interest, such as large deformation zones, are measured every quarter (Stöckel et al. 2013). On the footwall, the GPS measurements indicate only smooth continuous deformations, except in a limited area near the north end of the old open pit, which constitutes a distinct mining area called the Lake Ore. The orebody in this area (the Lake Ore) is treated as a separate body, i.e., it is not currently mined in sequence with the main orebody. In addition, the Lake Ore was not mined at all during the initial open pit exploitation. Instead, it was accessed at a later stage from underground mining, leaving a surface rock cap, which is now caving.

A number of distometer lines (wall-to-wall convergence) were installed starting in the mid-1980s, but by
2001, many were well inside the fractured volume and, hence, measurements were discontinued. Theodolite measurements were historically common in the underground mine. However, an evaluation presented in 2000 showed the bulk of the measurements to be questionable and the system fell out of use (Henry 2000).

A micro-seismic system aiming to cover the entire length of the orebody was installed in 2008. This system constituted roughly 220 geophones by the end of 2012 (Stöckel et al. 2013). The primary objective for the installation of the seismic system was to increase the understanding of the mine seismicity. This is done by tracking both events related to rock falls and bursts in active production areas, as well as events that seemingly do not cause stope damages. The knowledge gained is to be used for mining sequence optimization to ensure a high level of work safety; this has resulted in the bulk of the geophones being installed in close proximity to the mining areas, with few geophones in the upper $600 \mathrm{~m}$ of rock mass. The seismic system is currently the only systematic measuring system monitoring the footwall underground.

\subsection{Underground Damage Mapping}

Qualitative damage assessments are performed by routine damage mapping concentrated mostly near the production areas. The upper, decommissioned, areas are damage mapped only in relation to specific projects, which, in some cases, mean that several years might pass between the mapping occasions. Internal LKAB documents describe a number of such campaigns; the two most recent (current project excluded) were performed in 2004 and 2012, respectively, but they only covered the mine section Y22-Y24; see Fig. 1.

Within the current project, Nilsson et al. (2014) reported a damage mapping campaign performed between the coordinates Y15 and Y45 (roughly $3 \mathrm{~km}$ between the coordinates) during 2013. The aim was to update the underground observations on the decommissioned levels and to present them in the context of large-scale footwall fracturing. The footwall was systematically mapped for damage and fallouts on levels between 320 and $800 \mathrm{~m}$, more specifically, levels 320, 420, 509, 540, 740, and $775 \mathrm{~m}$.

Damage and fallouts were documented on mine maps covering the full horizontal orebody length. A line was drawn tracing the damage observations located farthest into the footwall. This resulted in a contour line on each mapped level. East of the line, the rock mass was considered damaged between the contour line and footwall-ore contact. To the west of the line, no damages were documented and, thus, the rock mass was considered undamaged. Damage originating from obvious local disturbances, such as highly weathered rock, was not used in the analysis. The contour lines on the respective levels were connected between levels 
by triangle elements. This facilitated the formation of a complex bounding surface (damage surface) indicating the boundary between the damaged and undamaged rock mass for the studied volume. A "construction" plane was then generated by tracing the line-of-sight projected edges of the contour lines at both ends of the orebody. This "construction" plane indicated the general dip and strike of the damage boundary surface and was used as a reference in the following figures for visualizing the uneven geometry of the boundary surface. The surface was colored using the "construction" plane as the spatial cut-off; the parts of the damage boundary surface that lay further east than the cutoff were colored red and the parts west of the cut-off were colored yellow. This could be interpreted as damage occurring deeper into the footwall in the areas indicated by yellow than in areas indicated by red. However, as the footwall contact is largely inaccessible, the undulating nature of the footwall contact itself could not be considered in this interpretation. The resulting surface is shown in Fig. 3. The construction plane was not, by itself, used for analysis, but was only used to color the damage boundary surface in order to highlight the geometrical features.

Nilsson et al. (2014) reported the shape of the damage boundary surface as being complex. The earlier postulated circular shear surfaces indicated by the numerical studies by, e.g., Sjöberg (1999) and Henry and Dahnér-Lindqvist (2000) were not discernible nor could any other clear mechanism be identified from the field observations or subsequent analysis.

By further studying the 3D surface, a number of conclusions related to the fracture behavior of the footwall were made, as follows:
- A continuous but complex damage boundary surface was approximated from the mapped damage. The movements in the footwall causing this damage had not yet been observed in the form of ground surface deformation. The surface deformation measurements by GPS monitoring only indicated small and continuous deformation.

- Comparing with previous mapping, it was clear that the progression of the damage surface into the footwall did not follow the mining depth linearly. The rate of progression seemed to be slower on shallow levels than on levels closer to the excavation level (i.e., deeper levels) during the studied period.

- At depths above mine level $740 \mathrm{~m}$, the observed fallouts appeared to be predominantly structurally controlled. Below level $740 \mathrm{~m}$, the damage seemed to be mainly stress induced. Distinction between preexisting and mining-induced fractures were made by examining fracture surfaces for weathering and infill, comparing fracture orientation to predominant joint orientations in the area (subjective comparison on-site), and comparing to damage patterns corresponding to known stress-damage mechanisms for the footwall as described by Edelbro et al. (2012).

Additional mapping was performed for this paper on levels not covered in the previous mapping campaign by Nilsson et al. (2014). These were mostly on the deeper levels: 795, 820, 878, and $907 \mathrm{~m}$. The results from this campaign were analyzed in the same way as that reported by Nilsson et al. (2014). This second mapping campaign showed similar patterns as reported above. It was also

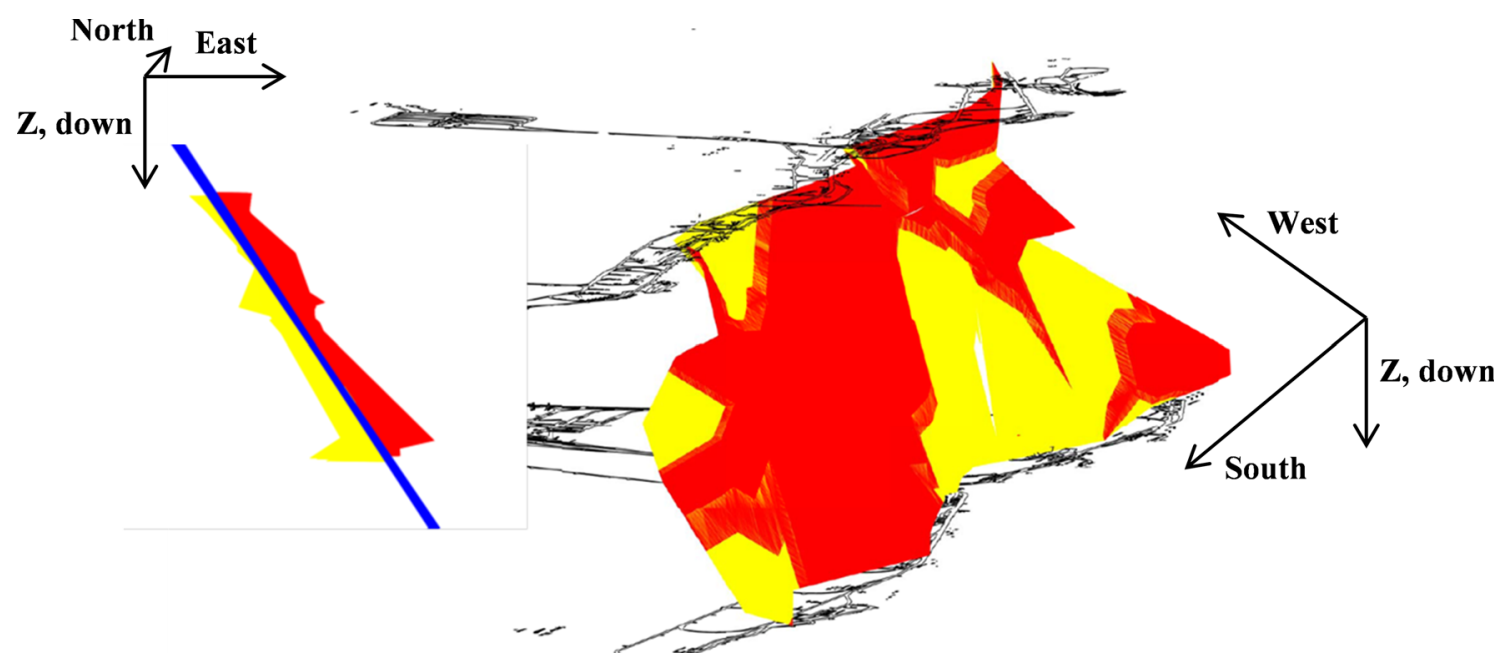

Fig. 3 Profile view of the damage surface with the "construction" plane in blue (left) and including layouts of levels 320 and $775 \mathrm{~m}$ in black (right), after Nilsson et al. (2014) (color figure online) 
noted that the conceptual damage boundary surface below level $795 \mathrm{~m}$ bends eastwards towards the SLC front and intersects the cave roughly on level $878 \mathrm{~m}$.

\section{Numerical Modeling of Large-scale Footwall Fracturing}

The mapping data present a good snapshot of the current damage situation underground. However, to understand the origin and development of the damaged volume, the behavior was studied through numerical modeling. The numerical models were based on data for section Y23 situated in the middle of the CA-area (Y21-Y25), which hosts most of the critical infrastructure (cf. Fig. 2). The CA-area has been inspected for damage on a regular basis throughout the mine's life. Y23 thus holds the best calibration data, as the failure development can be back-tracked from inspection notes over a long period.

\subsection{Modeling Approach and Numerical Code}

It was considered necessary to model the footwall-ore contact as a discontinuity, permitting opening and slip to allow the caved masses to move relative to the footwall in order to prevent excessive dragging effects. This implied modeling the footwall using both a continuum and a discontinuum approach, with the continuum behavior being related to the equivalent rock mass and the discontinuum behavior being related to slip along the footwall contact. Hence, the numerical code UDEC (Itasca Consulting Group, ICG 2011) was selected for the analyses because of its ability to simulate both continuous and discontinuous behavior. The validity of the $2 \mathrm{D}$ modeling approach has been shown by Malmgren and Sjöberg (2006), in which 2D and 3D model results of the Kiirunavaara mine were compared and it was concluded that a 2D model was sufficient to capture the stress state in the mid two-thirds of the mine (along the $y$ coordinate). Furthermore, Nilsson et al. (2014) also showed that a representative shape of the conceptual damage surface can be derived for any 2D mine cross-sections.

A perfectly plastic Mohr-Coulomb material was adopted for the rock mass in the numerical model. Primary inputs for the global rock mass were: internal cohesion $(c)$, internal friction angle $(\phi)$, tensile strength cut-off $\left(\sigma_{t}\right)$, and the elastic deformation parameters were: Young's modulus $(E)$ and Poisson's ratio $(v)$. A uniform density was applied for the entire rock mass at $2,700 \mathrm{~kg} / \mathrm{m}^{3}$. Excavation of production levels and subsequent caving of the hangingwall were modeled in three steps. Explicit modeling of discontinuities was used only for the post-excavation footwall contact, which was given properties of normal and shear stiffness $\left(K_{\mathrm{n}}\right.$ and $\left.K_{\mathrm{s}}\right)$, cohesion $(c)$, friction angle $(\phi)$, and tensile strength $\left(\sigma_{t}\right)$; the explicit values were referenced from Malmgren and Nordlund (2008).

The production levels were excavated using the FISH functions "Zonk" and "Relax" (Itasca Consulting Group, ICG 2011). The "Zonk" function automatically detects excavation voids within a model by identifying internal boundaries. During a fictitious excavation cycle, internal (reaction) forces are applied to the internal (excavation) boundary corresponding to the pressures expected to be applied from an unexcavated material. The "Zonk" companion function "Relax" gradually decreases the internal forces by ten equilibrium runs, ending with an applied force of 0 , which is the case of a fully excavated nonreinforced opening (Itasca Consulting Group, ICG 2011). This simulated gradual excavation process minimizes the "shock" in the model brought on by a sudden (instantaneous) removal of material from the model, which may otherwise generate reaction stress waves propagating from the newly formed void and overestimate yielding.

As the model reached equilibrium, the remaining "void" from excavation was backfilled by low-stiffness cave rock; at the same time, the portion of the hangingwall overlying the excavated zones was converted to cave rock. The model was then run again to equilibrium, finalizing the mining sequence of the level.

\subsection{Model Setup}

A model sized 4,000 $\mathrm{m}$ (width) by 2,800 $\mathrm{m}$ (height) was constructed. These model dimensions were consistent with the global model dimension used earlier by, e.g., Malmgren and Sjöberg (2006). The surface features of the open pit, such as the pit bottom, slopes, and crests, were referenced and simplified from the LKAB mine maps and then built into the model. The open pit bottom was estimated to be at mine level $300 \mathrm{~m}$, the footwall crest at level $60 \mathrm{~m}$, and the hangingwall crest at level $200 \mathrm{~m}$ (Z-zero is defined at the now removed pre-mining peak of the Kiirunavaara mountain). Excavation level floors were added at every $30 \mathrm{~m}$, with the first floor at level $330 \mathrm{~m}$ and the last at level $1,110 \mathrm{~m}$. A total of 27 excavation steps were prepared. For each excavation step, a vertical "cave column" was defined, constituting the hangingwall zones overlying the excavation block. The model was zoned with a uniform edge length of $15 \mathrm{~m}$. As mining was simulated, the footwall-ore contact was unlocked and allowed to respond to the changes in stress state. The final model geometry is shown in Fig. 4.

The initial stresses applied to the model are shown in Table 1. The in-plane horizontal stress corresponds to the major horizontal stress component, which is aligned perpendicular to the orebody, while the out-of-plane horizontal stress corresponds to the minor horizontal stress component, which is aligned parallel to the strike of the orebody. 
Fig. 4 Model setup based on a vertical cross-section across the orebody

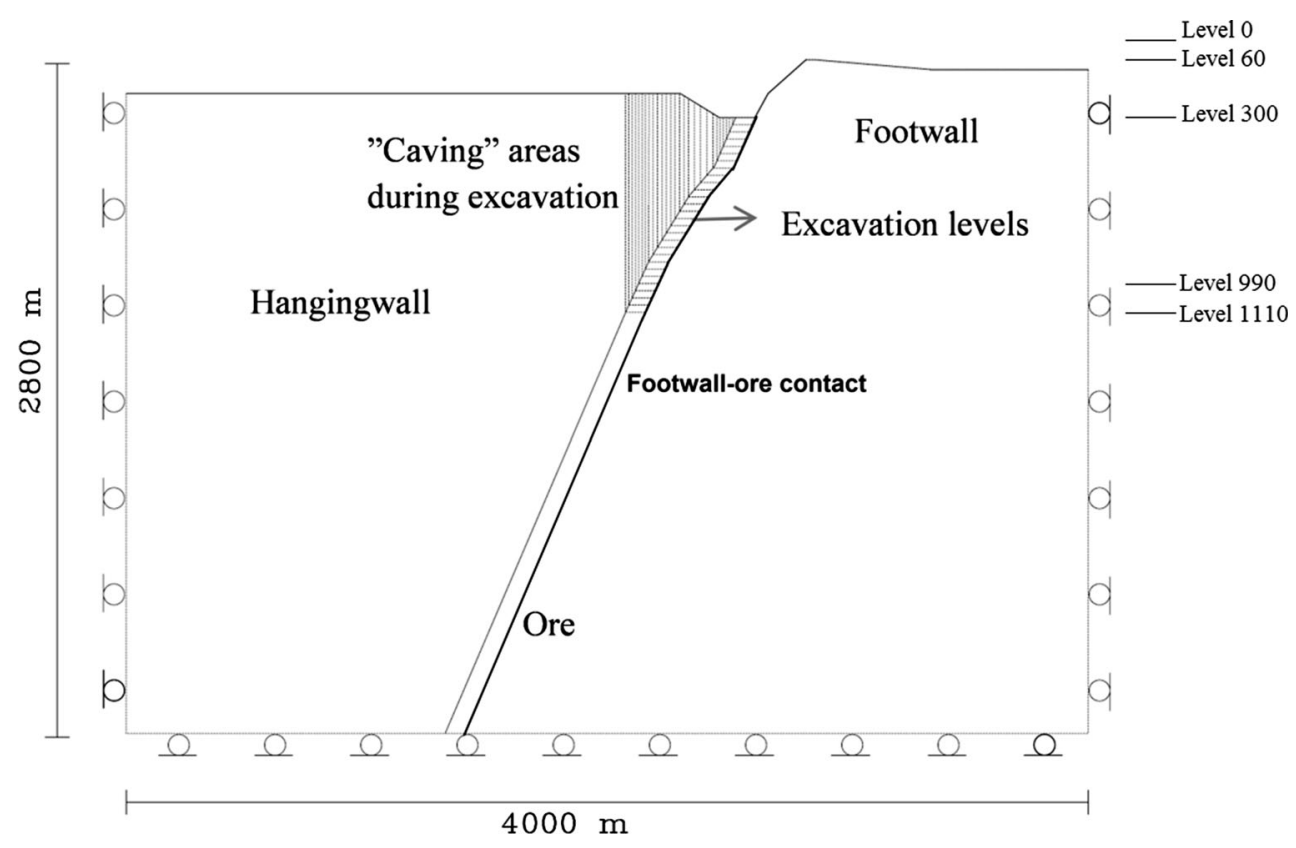

Table 1 Initialized stresses, adapted from Sandström (2003)

\begin{tabular}{llll}
\hline Stress type & $\sigma_{x}$ (in-plane horizontal) & $\sigma_{y}$ (in-plane vertical) & $\sigma_{z}$ (out-of-plane horizontal) \\
\hline Magnitude $(\mathrm{MPa})$ & $2.22+0.037 y$ & $1.74+0.029 y$ & $1.68+0.028 y$ \\
\hline
\end{tabular}

Table 2 Joint parameters (Malmgren and Nordlund 2008)

\begin{tabular}{lllll}
\hline$k_{\mathrm{n}}(\mathrm{GPa} / \mathrm{m})$ & $k_{\mathrm{s}}(\mathrm{GPa} / \mathrm{m})$ & $c(\mathrm{MPa})$ & $\phi\left(^{\circ}\right)$ & $\sigma_{\mathrm{t}}(\mathrm{MPa})$ \\
\hline 110 & 9 & 0 & 35 & 0 \\
\hline
\end{tabular}

Table 3 Caved rock parameters (Villegas et al. 2013)

\begin{tabular}{lllll}
\hline$E(\mathrm{GPa})$ & $c(\mathrm{MPa})$ & $\phi\left(^{\circ}\right)$ & $\sigma_{\mathrm{t}}(\mathrm{MPa})$ & $\rho\left(\mathrm{kg} / \mathrm{m}^{3}\right)$ \\
\hline 0.2 & 0 & 35 & 0 & 2,000 \\
\hline
\end{tabular}

The in-plane vertical stress corresponds to the in situ vertical stress component. The depth dependent variables in Table 1 were referenced from Sandström (2003), while the constant values were chosen so that all stresses were equal to zero at the footwall crest at level $60 \mathrm{~m}$ (model $y$-axis -60). Compressive stresses are denoted as negative. Input parameters for the footwall contact and the caved rock are presented in Tables 2 and 3, respectively.

\section{Modeling Results}

\subsection{Parametric Study}

A parametric study was conducted for a vertical 2D crosssection. The rock mass inputs are shown in Tables 2, 3, and 4. The input parameters in Table $4, c, \phi, \sigma_{\mathrm{t}}$, as well as
$E$ and $v$, were calibrated until the yielded elements and shear strain concentrations approximated the evolution of the damage boundary surface as mapped at the studied mine profile. The primary aim of the analysis was to identify parameters with a strong influence on the modeling results in order to judge the sensitivity of the results related to changes in the input parameters. As a secondary objective, the results were compared to the calibration data (the conceptual damage surface) to find "best fit" parameters for studying the rock mass behavior.

The sensitivity of the rock mass behavior to variations in the mechanical parameters was evaluated by varying one parameter at a time (within plausible limits derived from the literature), while keeping all the others constant (see Table 5). The initial parameter values for each set of analyses were retrieved from the literature on the Kiirunavaara footwall as shown in Table 4. Each parameter was varied within the ranges found in the examined literature to evaluate the impact on predominant failure mechanisms. The sensitivity in the plastic response, in terms of yielded elements and shear strain concentrations, was evaluated. Some key results from the sensitivity study are presented. For visualization purposes, the principal results are plotted for excavation down to level $990 \mathrm{~m}$ (currently an active level). The plot outline cut-off for shear strain is $0.05 \%$ if not stated otherwise. 
Table 4 Rock mass parameters from the literature cases

\begin{tabular}{llllll}
\hline Source & $E(\mathrm{GPa}) / v$ & $c(\mathrm{MPa})$ & $\phi\left(^{\circ}\right)$ & $\sigma_{\mathrm{t}}(\mathrm{MPa})$ & Note \\
\hline Literature cases & & & & & \\
$\quad$ Dahnér-Lindqvist (1992) & $18 / 0.25^{\mathrm{a}}$ & 1.5 & 30 & 0.8 & Study used empirical charts \\
Sjöberg (1999) & $60 / 0.25$ & 0.4 & 35 & 0.3 & Numerical study in FLAC \\
Villegas et al. (2013) & $13 / 0.22$ & 1 & 37 & 0.8 & Numerical study in FLAC \\
Henry (2000) & $18 / 0.25^{\mathrm{a}}$ & 6 & 35 & 0.4 & Review of LKAB internal numerical and empirical analyses \\
Perman and Sjöberg (2011) & $70 / 0.25$ & 6.67 & 52.9 & 1.3 & $\begin{array}{c}\text { Numerical study in 3DEC, values named "low" values were } \\
\text { picked up from the study }\end{array}$
\end{tabular}

a The deformation parameters were not given by the reference case and were, thus, estimated from the footwall RMR referenced from Sandström (2003) and the simplified Hoek and Diederichs equation by Hoek and Diederichs (2006) with $D=0$. The Poisson's ratio was set to 0.25 , as chosen by Sjöberg et al. (2001) and Perman and Sjöberg (2011)

Table 5 Initial inputs used for the sensitivity analyses

\begin{tabular}{|c|c|c|c|c|c|}
\hline $\begin{array}{l}\text { Sensitivity } \\
\text { analysis }\end{array}$ & $\begin{array}{l}\text { Parameter } \\
\text { varied }\end{array}$ & $E(\mathrm{GPa}) / v$ & $c(\mathrm{MPa})$ & $\begin{array}{l}\phi \\
\left({ }^{\circ}\right)\end{array}$ & $\begin{array}{l}\sigma_{\mathrm{t}} \\
(\mathrm{MPa})\end{array}$ \\
\hline 1 & $\sigma_{\mathrm{t}}$ & $13 / 0.22$ & 2 & 35 & $\begin{array}{l}0.4 \\
0.8 \\
1.0 \\
1.3\end{array}$ \\
\hline 2 & $\mathrm{c}$ & $70 / 0.25$ & $\begin{array}{l}0.1 \\
0.2 \\
0.4\end{array}$ & 35 & 1.3 \\
\hline 3 & $\phi$ & $70 / 0.25$ & 0.4 & $\begin{array}{l}30 \\
35 \\
40\end{array}$ & 1.3 \\
\hline 4 & $E / v$ & $\begin{array}{l}60 / 0.25 \\
13 / 0.22\end{array}$ & 0.4 & 35 & 0.3 \\
\hline 5 & & $\begin{array}{l}70 / 0.25 \\
13 / 0.22\end{array}$ & 0.4 & 35 & 0.8 \\
\hline
\end{tabular}

In the first sensitivity analysis (Table 5), the sensitivity of the model to variations in the tensile strength was evaluated. The tensile strength was varied (over the range of published values) from 1.3 to $0.4 \mathrm{MPa}$ in three steps. The principal results using tensile strengths of $1.3,0.8$, and $0.4 \mathrm{MPa}$ are shown in Fig. 5. The influence of the variation in the tensile strength is insignificant near the footwall-ore contact. Farther into the wall, a lower tensile strength incurs an increased development of tensile failure from the footwall ground surface; this increase was observed to be significant only for the final reduction step from 0.8 to $0.4 \mathrm{MPa}$.

For the second analysis, the internal cohesion was varied (over the range of published values) between 0.4 and $0.1 \mathrm{MPa}$ in two steps (see Table 5); the principal results are shown in Fig. 6. The boundary of the yielded area is virtually unchanged within the set. However, as can be noted, the extent and position of the shear strain concentrations are notably affected. The decrease in cohesion facilitates the formation of "shear bands" in the middle portion of the slope, as well as a general increase in the number of affected zones.

In the third analysis, the internal friction angle was varied (over the range of published values) from $40^{\circ}$ to $30^{\circ}$ in two steps. Similar to the changes in internal cohesion, only marginal differences were observed in the outline of yielded zones, while a significant increase in shear band growth was noted in the shear strain concentration plots, as shown in Fig. 7.

In the fourth analysis, the influence of the elastic parameter magnitude was briefly examined. Two combinations of elastic parameters were used based on the literature as $E=70 \mathrm{GPa}, v=0.25$ and $E=13 \mathrm{GPa}, v=0.22$, respectively. Shear strain concentrations were plotted for both combinations and compared; see Fig. 8. Note that the contour interval for the shear strain concentrations differs between plots A and B in Fig. 8. The magnitude of the elastic parameters significantly influences the magnitude of the calculated shear strain, but not the spatial location of the shear strain concentration ("shear band formation"). The influence on the extent of the yielded zone was negligible, as expected. Thus, for the subsequent analyses, the models were assumed to be insensitive to magnitude variations of the elastic constants within the studied span when only localization of strain concentrations and element yielding were used for evaluating plastic response.

The results from the sensitivity analyses show that, with the current model setup:

- Variations of $E$ and $v$ have an insignificant effect on the amount and extent of yielding.

- Variations in $\sigma_{\mathrm{t}}$ have a minor effect on plastic response when $c$ is set high or low.

- Variations in $c$ have a significant effect on plastic response when $\sigma_{\mathrm{t}}$ is high. 
Fig. 5 Principal outlines of relative plastic response for changes in the tensile strength, with the original block geometry as a blue wireframe (color figure online)

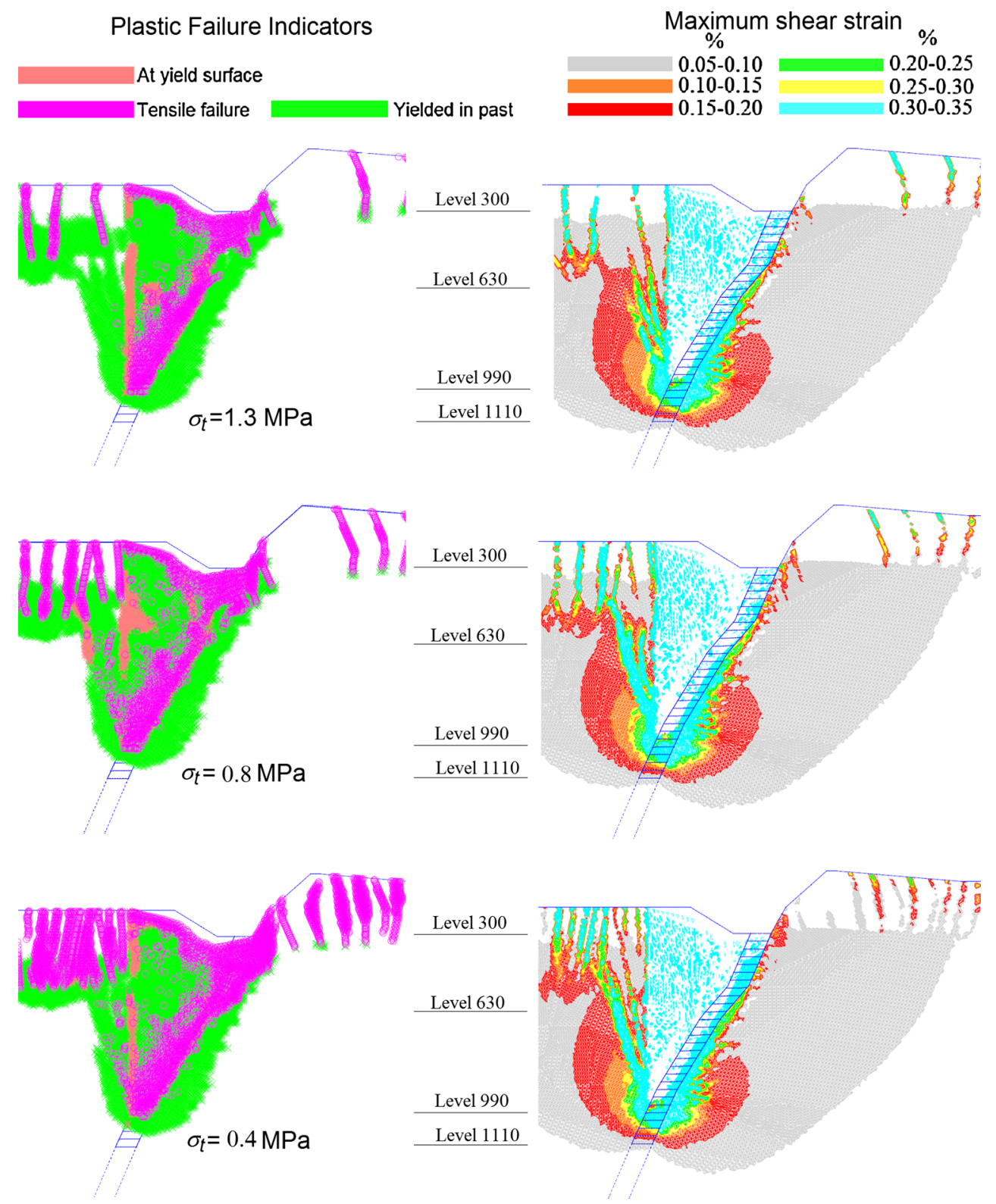

- Variations in $\phi$ have a significant effect on plastic response when $c$ is low and $\sigma_{\mathrm{t}}$ is high.

It should also be noted that the increase in tensile failure indicators for the high cohesion models (first analysis) could not be directly evaluated in models using lower cohesion values when studying the yielded zone plots alone. Using internal cohesion values similar to those in the other sets (analyses 2 and 3) produced relatively large numbers of yielded zones near the ground surface, making the distinction between tensile and shear failure from plastic indicators alone impractical (plots not included). However, the observations on shear strain concentration being marginally affected by changes in the tensile strength holds also for lower values of internal cohesion down to $0.3 \mathrm{MPa}$.

The parametric study was used to identify the predominantly occurring failure modes and, subsequently, formed the basis for model calibration to fit the numerical behavior to the damages observed and inferred from the field. As such, the study included just over 30 parameter combinations, which are not all reported in this paper due to the similarities between many of the cases where the influence from parameter changes was only apparent when studying the results in great detail. The small effects on the overall behavior resulting from changes of $\sigma_{t}$, for both low and high values (relative to the examined literature cases), 
Fig. 6 Principal outlines of relative plastic response for changes in the internal cohesion, with the original block geometry as a blue wireframe (color figure online)

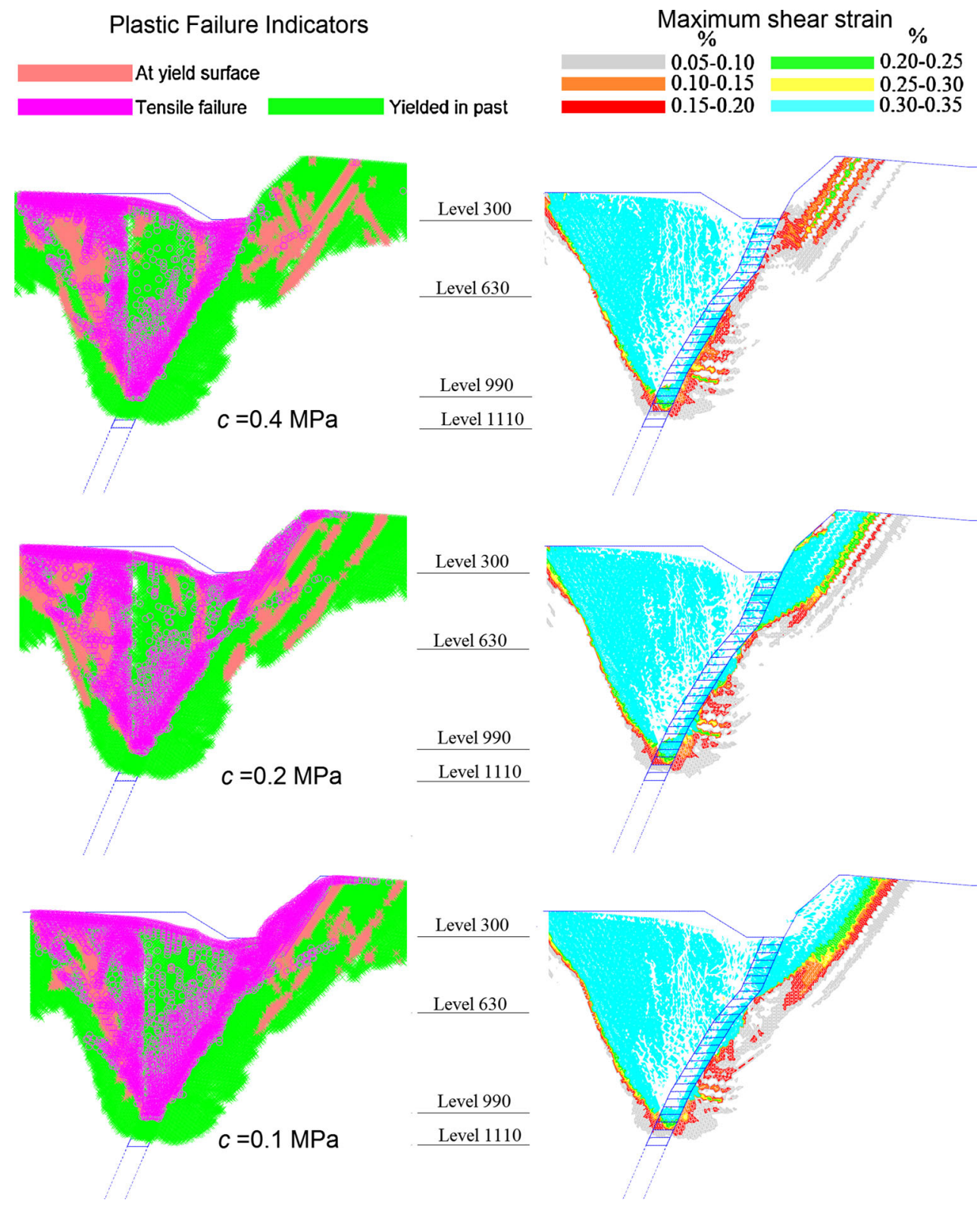

were interpreted to mean that tensile failure would be an unlikely global failure mode in the footwall. However, the model cases featuring low values of $\sigma_{\mathrm{t}}$ (e.g., analysis 1 , step 3) indicated excessive tensile yielding outside the studied area (tensile crack development from the ground surface "behind" the footwall crest). This tensile crack development was strongly related to the use of an equivalent rock mass approach. In the in situ environment, this is associated with the opening (normal displacement) of unfavorable oriented joints or tensile cracks. As no "discontinuity opening" is possible within the numerical block, the tensile stresses in the model are, instead, transferred to adjacent zones, leading to excessive indications of yield. To minimize this effect, the tensile strength was set to the highest value, as it was shown that tensile failure would not occur in the studied area for low values of $\sigma_{t}$, even if shear failure was counteracted by a high set of internal cohesion (sensitivity analysis 1, Fig. 5). This approach was considered valid as the models were not used to evaluate ground surface subsidence but the failure development close to the footwall contact.

\subsection{Model Calibration}

The final results from the sensitivity analysis were used to generate additional models. These were then evaluated in order to determine the parameter combinations for which the results would best approximate the observed damage 
Fig. 7 Principal outlines of relative plastic response for changes in the internal friction angle, with the original block geometry as a blue wireframe (color figure online)

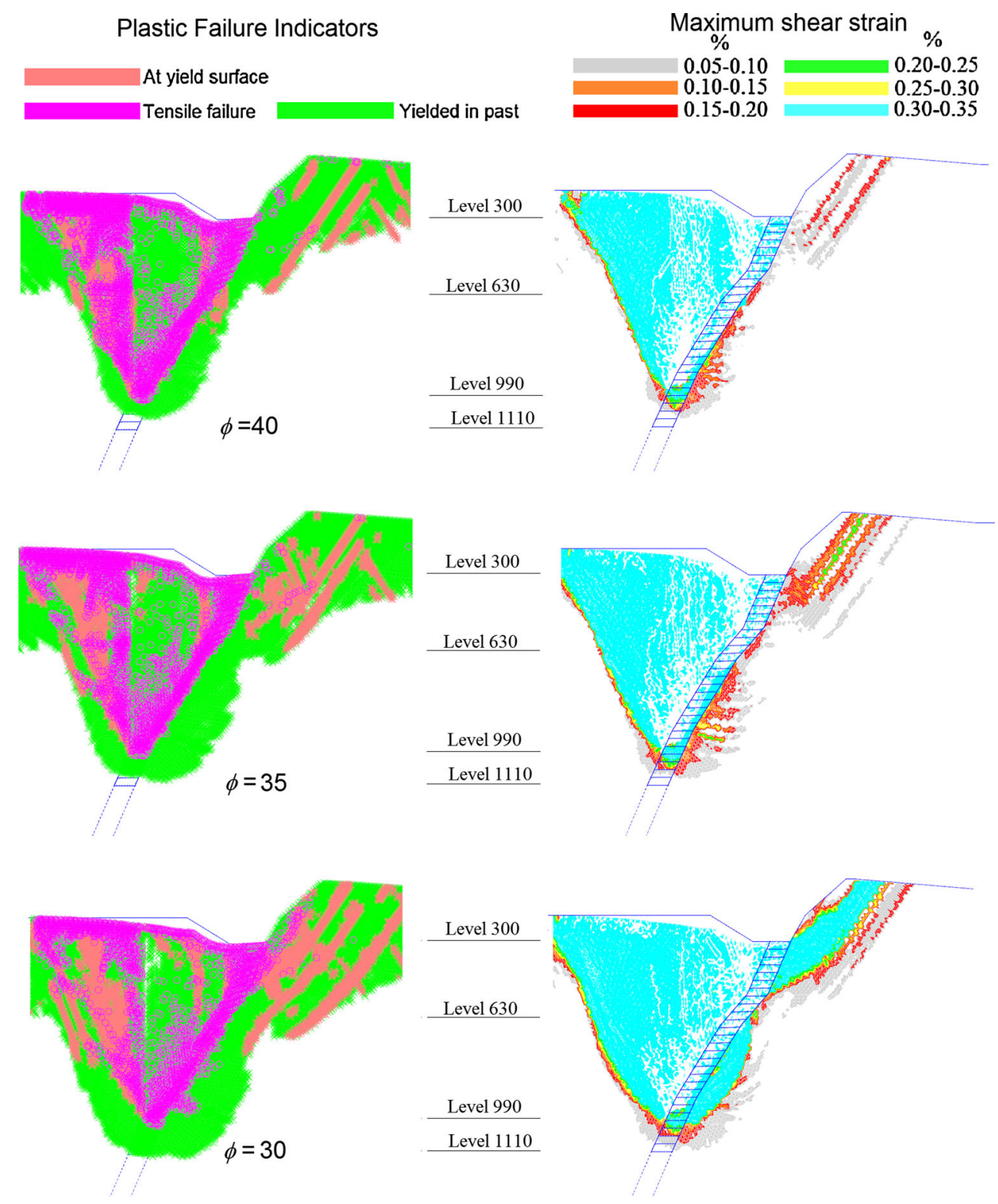

from the field. The cases with the closest match, presented in Table 6, were then selected for further analyses.

The parameter choice was based primarily on shear strain concentrations and secondarily on yielded zones. Three types of shear strain concentrations were examined:

(I) The formation of shear bands which would coincide with the conceptual damage boundary from the mapping campaign.

(II) Shear strain zones originating from the excavation area whose continuation into the footwall would "bind" together the conceptual damage boundary in the upper part of the footwall with the production area.

(III) The formation of shear bands (subparallel to the observed damage) which would be located further into the footwall than can be confirmed from the current infrastructure.

The theory behind (I) and (III) is fairly well established; if shear bands connect between two distinct surfaces, a (often circular) shear failure is indicated. The assumption behind (II) is less general and requires some geomechanical prerequisites of the rock mass to be satisfied to have a clear physical meaning. The damage mapping campaign showed that the stope damage was predominantly structurally controlled above level $740 \mathrm{~m}$. This means that the rock mass was mobilized primarily by sliding on, or opening of, preexisting discontinuities (often) running subparallel to the ore contact. However, this mobilization requires movement at the toe of the structurally controlled 
Fig. 8 Contours of shear strain concentrations for plastic models with differing elastic input parameters, with the original block geometry as a blue wireframe (color figure online)
A $E=70 \mathrm{GPa} v=0.25$; shear strain interval $0.05-0.35 \%$

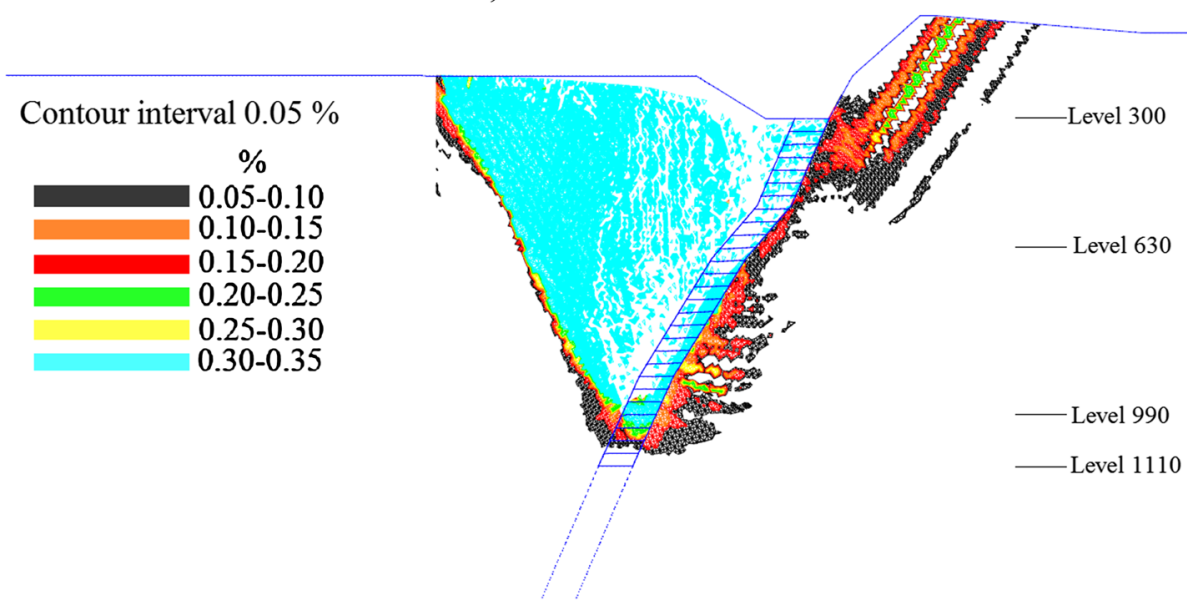

B $E=13$ GPa $v=0.22$; shear strain interval $0.2-1.4 \%$

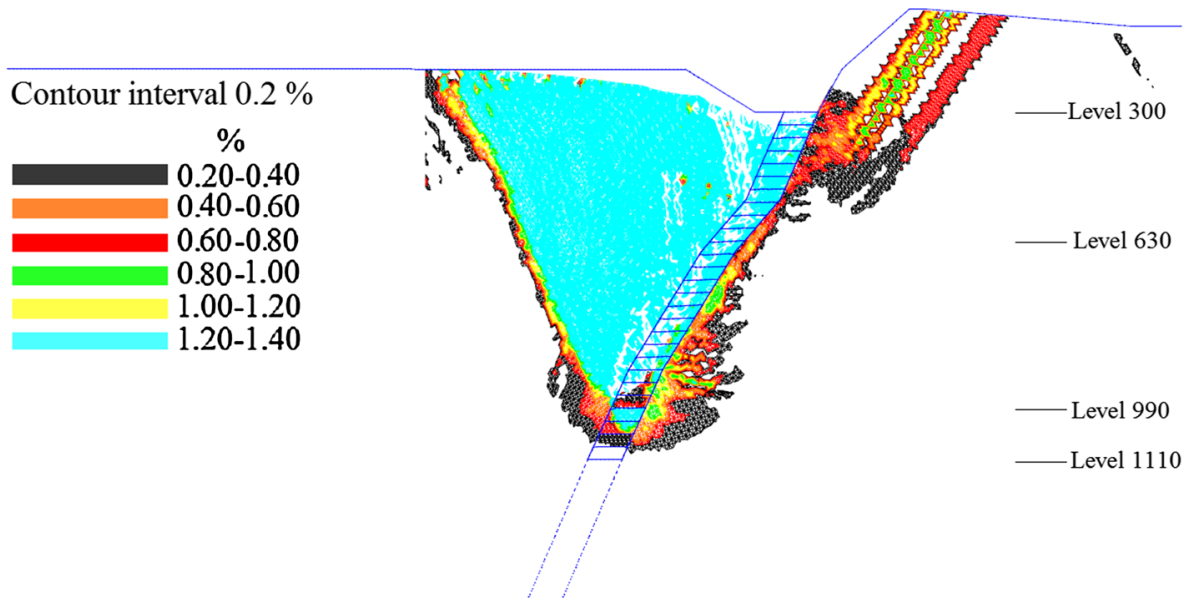

Table 6 Closest match parameter combinations from the sensitivity analyses

\begin{tabular}{lllll}
\hline Case number & $E(\mathrm{GPa}) / v$ & $c(\mathrm{MPa})$ & $\phi\left({ }^{\circ}\right)$ & $\sigma_{\mathrm{t}}(\mathrm{MPa})$ \\
\hline 1 & $60 / 0.25$ & 0.1 & 35 & 0.3 \\
2 & $70 / 0.25$ & 0.4 & 30 & 1.3 \\
3 & $13 / 0.22$ & 0.8 & 35 & 0.8 \\
4 & $18 / 0.25$ & 0.6 & 35 & 0.4 \\
5 & $13 / 0.22$ & 1.2 & 35 & 0.8 \\
6 & $18 / 0.25$ & 1.5 & 30 & 0.8 \\
\hline
\end{tabular}

failure, e.g., through a step-path type rock mass failure.

\subsubsection{Case Analysis}

From the cases presented in Table 6, three distinct behaviors were simulated, which could all be correlated to the observed damage as the simulation reached the current production level of the studied block, i.e., level $990 \mathrm{~m}$. The sensitivity analysis indicated that the cohesion $(c)$ and internal friction angle $(\phi)$ significantly affected the model behavior, while tensile strength $\left(\sigma_{t}\right)$ and deformation parameters $(E$ and $v$ ) had a lesser influence. This was again made apparent by sorting the set-ups from Table 6 with respect to cohesion and internal friction angle. Sorting with respect to these strength parameters also facilitated the cases to be categorized with respect to the inferred failure mode; see Table 7.

\subsection{Choice of Base Case}

As indicated in Fig. 9, the observed damage could be explained by three distinct evolution paths. However, Fig. 10 indicates excessive element yielding for cases of low to moderate cohesion values. It was concluded that the most likely failure evolution path was described by the parameter combination depicted in Figs. 9e and 10e. Case 5 was, therefore, denoted as the "base case". In the base 
Table 7 Results from analysis cases which approximated the observed damage

\begin{tabular}{|c|c|c|c|c|c|}
\hline Inferred footwall slope failure & Case number & $E(\mathrm{GPa}) / v$ & $c(\mathrm{MPa})$ & $\phi\left(^{\circ}\right)$ & $\sigma_{\mathrm{t}}(\mathrm{MPa})$ \\
\hline Top of footwall crest is sheared-theory (I) & Case 1, Figs. 9a and 10a & $60 / 0.25$ & 0.1 & 35 & 0.3 \\
\hline Top of footwall crest is sheared-theory (I) & Case 2, Figs. $9 \mathrm{~b}$ and $10 \mathrm{~b}$ & $70 / 0.25$ & 0.4 & 30 & 1.3 \\
\hline $\begin{array}{l}\text { Shear bands connect the observed damage surface with the ground } \\
\text { surface-theory (III) }\end{array}$ & Case 3, Figs. 9c and 10c & $13 / 0.22$ & 0.8 & 35 & 0.8 \\
\hline $\begin{array}{l}\text { Shear bands connect the observed damage surface with the ground } \\
\text { surface-theory (III) }\end{array}$ & Case 4, Figs. 9d and 10d & $18 / 0.25$ & 0.6 & 35 & 0.4 \\
\hline $\begin{array}{l}\text { A shear "cut-off" is formed between the observed damage surface } \\
\text { and the cave zone-theory (II) }\end{array}$ & Case 5, Figs. 9e and 10e & $13 / 0.22$ & 1.2 & 35 & 0.8 \\
\hline $\begin{array}{l}\text { A shear "cut-off" is formed between the observed damage surface } \\
\text { and the cave zone-theory (II) }\end{array}$ & Case 6, Figs. 9f and 10f & $18 / 0.25$ & 1.5 & 35 & 0.8 \\
\hline
\end{tabular}

case, the pattern of shear strain concentrations from the excavation front intersects with the observed structurally controlled failure, resulting in a step-path type failure developing in the model (but without explicit step-path joints being modeled). This step-path is also indicated by the mapping results where damage underlying level $740 \mathrm{~m}$ was deemed to be mainly stress-induced, including propagation of new fractures. As the rock mass expands into the lowstiffness cave material from the SLC operation, it becomes de-stressed. This results in the softened rock mass failing along a curved shear failure surface, as illustrated in Fig. 12. The shear failure intersects and mobilizes the structures controlling the failure on the shallow levels. For case 5, it is indicated in both Figs. 9e and 10e that the damage would not follow the ore contact at shallow levels but, instead, daylight in the open pit slope. This failure path observation is supported both by earlier internal reports of the presence of a subvertical structure within the vicinity of level $300 \mathrm{~m}$, as well as the fact that, despite the damages observed underground, only minor and continuous deformation have been observed on the ground surface (outside the caving zone). The proposed evolution path of the largescale fracturing indicated by the base case in combination with on-site observations is conceptually shown in Fig. 11. A possible daylight of the subvertical structure is shown in Fig. 13.

\subsection{Considerations for the Monitoring System}

It appears that a system for monitoring the long-term largescale footwall fracturing needs to function under a variety of conditions, as the mapping and numerical analyses show that the damage zone behavior will be different at shallow and deep levels. Indeed, both the mapping data and the numerical models suggest that the fracturing is most active in the lower portions of the footwall slope. This conclusion is also supported by micro-seismic localization data indicating very low activity at shallow levels (Svartsjaern 2015). In combination, mapping and numerical modeling data suggest that the conceptual damage boundary surface follows pre-existing discontinuities in the upper and mid portions of the footwall. Under these conditions, the damage extent will be limited by the activation of these discontinuities at deeper levels and can, thus, be expected to move into the footwall in a step-by-step fashion, with the step length set by the spacing of the discontinuities. This means that the damage extent boundary, when moving inwards, will do so by stepping to the next set of discontinuities without significant damage to the rock mass between discontinuities prior to the "step"; see Fig. 14. A monitoring system should, thus, be required to be able to detect or capture such behavior in the rock mass.

Any monitoring system installed in the upper parts of the mine must tolerate large shear deformations concentrated in narrow regions (shearing of structures), while still being able to also detect mobilization of new structures located potentially tens of meters farther into the footwall. In the planned monitoring, this will be achieved by installing multiple diameter time-domain reflectometry (TDR) cables in boreholes drilled (as far as practically possible) perpendicularly through the conceptual damage surface. The multiple diameter TDR will allow the smaller diameter cables to accurately monitor the shearing of structures, while the larger diameter cables will ensure continued monitoring even if relatively large movements develop in any specific structure. In addition, the extension of drifts running perpendicular to the orebody strike is recommended to be monitored by means of a tape extensometer to detect rock mass movement towards the cave zone.

For deeper levels, the monitoring system should accommodate both shear and extensional movements within 

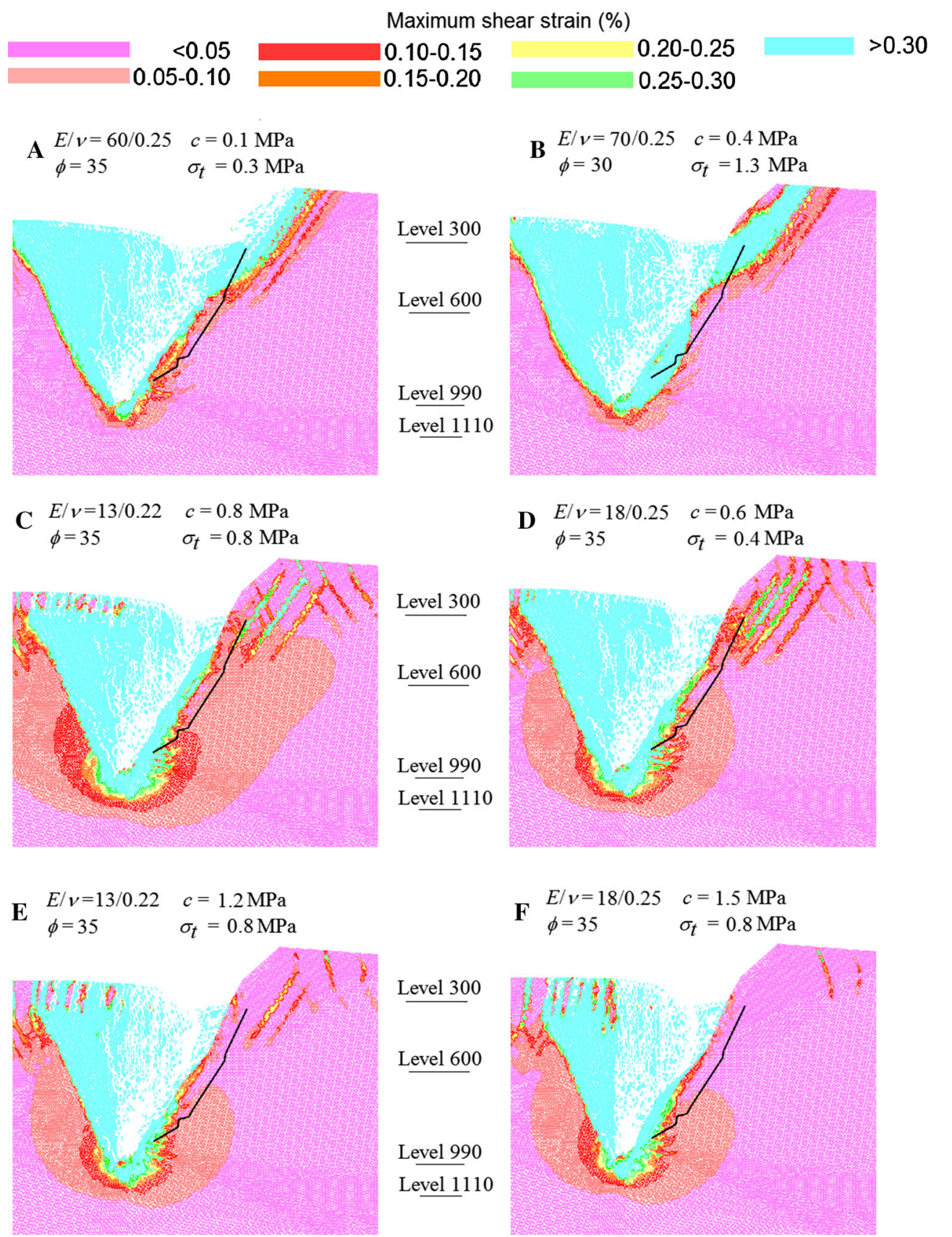

\section{Level 300
Level 600
Level 990
Level 1110}

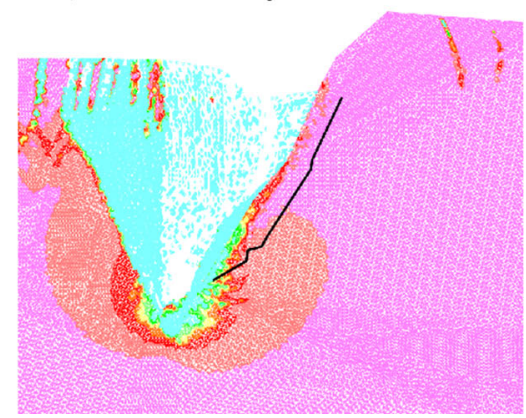

Fig. 9 Relative shear strain concentrations with input properties according to Tables 2, 3, and 7 for mining to the $990 \mathrm{~m}$ level. The black lines indicate the estimated position of the damage extent border from field observations

the rock mass. Just as in the upper levels, the shear displacements should be captured by, e.g., using multiple diameter TDR cables installed in boreholes drilled through the step-path zone. In addition, extensometers should be installed parallel to the TDR cables to help in differentiating the shear displacements from extensional rock mass deformations.

\section{Discussion}

The failure evolution path indicated in Fig. 11 involves two distinct types of failure mechanisms. At shallow levels (above level $740 \mathrm{~m}$ ), structurally controlled stope damages along pre-existing structures are observed, whereas at deeper levels, step-path type failures through rock bridges 
Plastic failure indicators

At yield surface
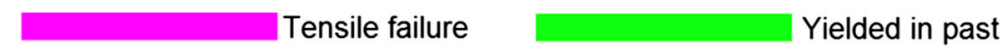

$$
\mathbf{A} \begin{array}{ll}
E / v=60 / 0.25 & c=0.1 \mathrm{MPa} \\
\phi=35 & \sigma_{t}=0.3 \mathrm{MPa}
\end{array}
$$

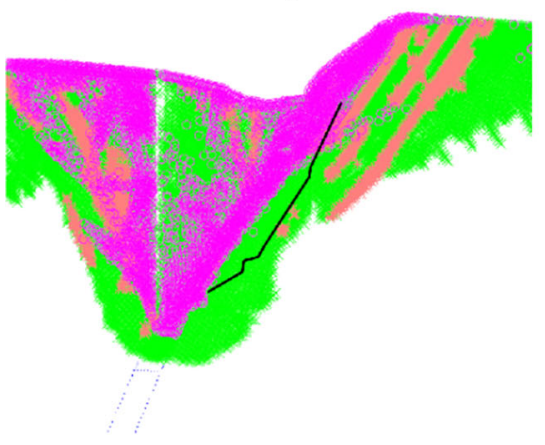

$\begin{array}{cc}\mathbf{C}=13 / 0.22 & c=0.8 \mathrm{MPa} \\ \phi=35 & \sigma_{t}=0.8 \mathrm{MPa}\end{array}$

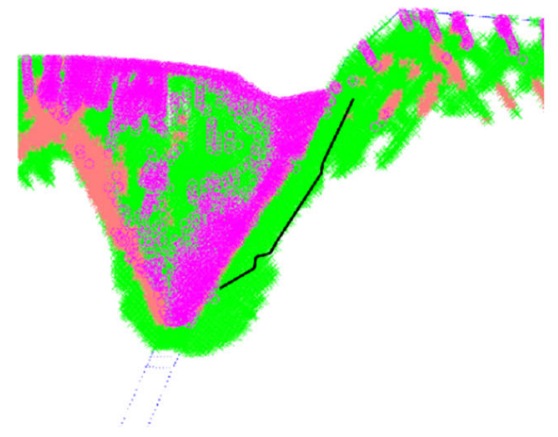

$\begin{array}{cl}\mathbf{E} E / \nu=13 / 0.22 & c=1.2 \mathrm{MPa} \\ \phi=35 & \sigma_{t}=0.8 \mathrm{MPa}\end{array}$

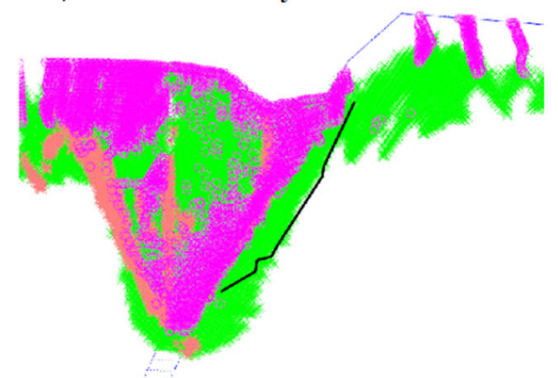

B $E / v=70 / 0.25 \quad c=0.4 \mathrm{MPa}$

$\phi=30$

$\sigma_{t}=1.3 \mathrm{MPa}$

Level 300

Level 600

Level 990

Level 1110

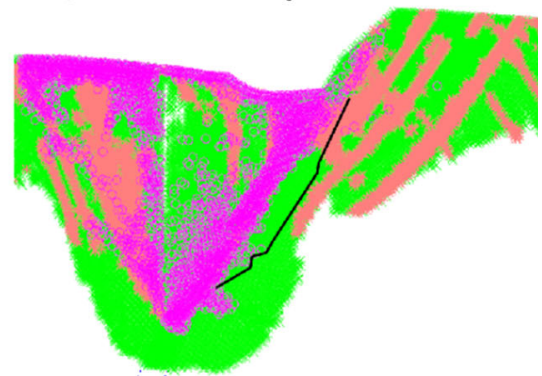

D $E / v=18 / 0.25 c=0.6 \mathrm{MPa}$

$\phi=35 \quad \sigma_{t}=0.4 \mathrm{MPa}$

Level 300

Level 600

Level 990

Level 1110

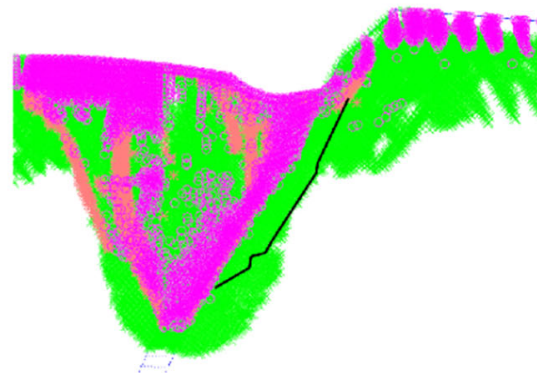

F $\begin{array}{ll}E / v=18 / 0.25 & c=1.5 \mathrm{MPa} \\ \phi=35 & \sigma_{t}=0.8 \mathrm{MPa}\end{array}$

Level 300

Level 600

Level 990

Level 1110

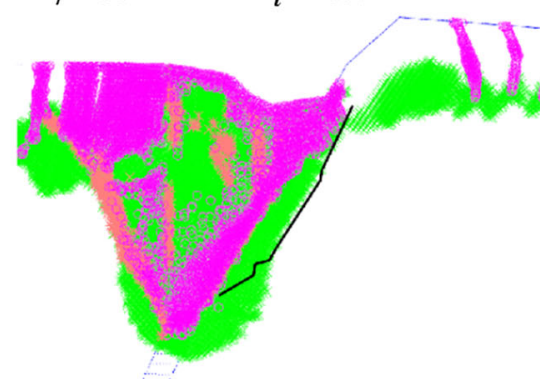

Fig. 10 Yielded elements with input properties according to Tables 2, 3, and 7 for mining to the $990 \mathrm{~m}$ level. The black lines indicate the estimated position of the damage extent border from field observations

are inferred by site observations and the numerical models. Thus, two types of damage evolution are anticipated. At shallow levels, the damage extent will likely follow structures subparallel to the ore contact. However, this damage is not considered likely to progress farther into the footwall as long as the toe of the failure is confined. Sliding along the structures requires a rotational movement of the rock mass at deep levels towards the excavation area, which could be facilitated by a curved shear surface intersecting both the structures in question and the SLC zone. In the current case, this curved shear surface is assumed as a step-path type failure where intact rock bridges between ore-parallel structures are fractured due to high concentrations of shear strain. It can, thus, be postulated that the 
Fig. 11 Proposed conceptual evolution path of the large-scale fracturing indicated by the base case model

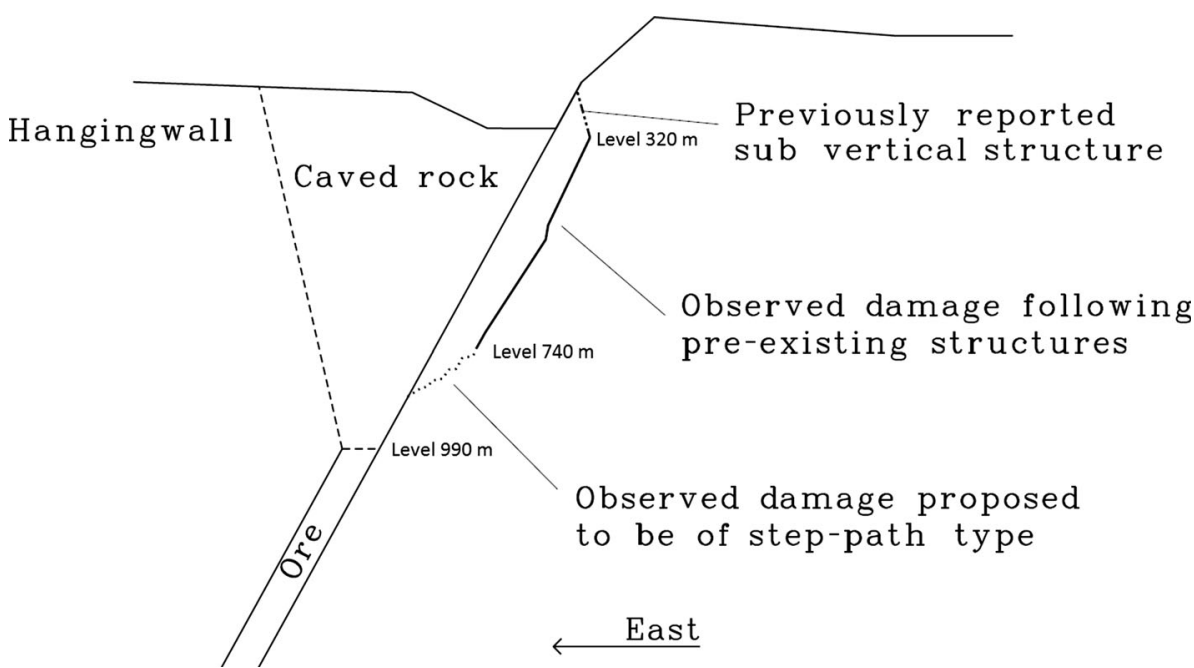

For example, Dahnér-Lindqvist (1992) based their analysis on empirical slope stability charts presented by Hoek and Bray (1981), while Perman and Sjöberg (2011) used a global-local model approach to study failure on the stope scale. Henry (2000) studied the footwall fracturing with respect to the water pump network (transporting water from the mine to the ground surface) and based their conclusion on both empirical charts as well as numerical modeling by other authors. Villegas et al. (2013) were primarily interested in the hangingwall. The closest match to the current modeling aim was found in the stability analysis by Sjöberg (1999).

Due to the validation approach (back-analysis with failure replication) used for the parametric study, which concentrated on the behavior and failure mechanisms of the footwall, some of the parameter combinations used would fit poorly to conventional Mohr-Coulomb failure envelopes. This was caused by some failures being "forced" by artificially preventing others, e.g., forcing tensile failure by applying a high internal cohesion combined with a low tensile cut-off. For some cases, tensile failure was inhibited away from the studied area by the application of a higher tensile strength than warranted by the internal cohesioninternal friction combination. This was considered to be a viable approach as the parameter study showed tensile failures in the studied area to be unlikely, even at low tensile strengths. The base case parameter combination best approximated the inferred failures from the field observations by adequately simulating the equivalent rock mass response but not necessarily the "actual" rock mass properties. This limits the possible uses for the current models outside the intended purpose.

All numerical models are sensitive to the input parameters. Even so, the geometry and geology must, in all cases, be simplified. The choice to use the equivalent rock 
Fig. 13 Daylight of a subvertical structure in the open pit footwall possibly intersecting the damage surface underground (coordinates are only approximate)

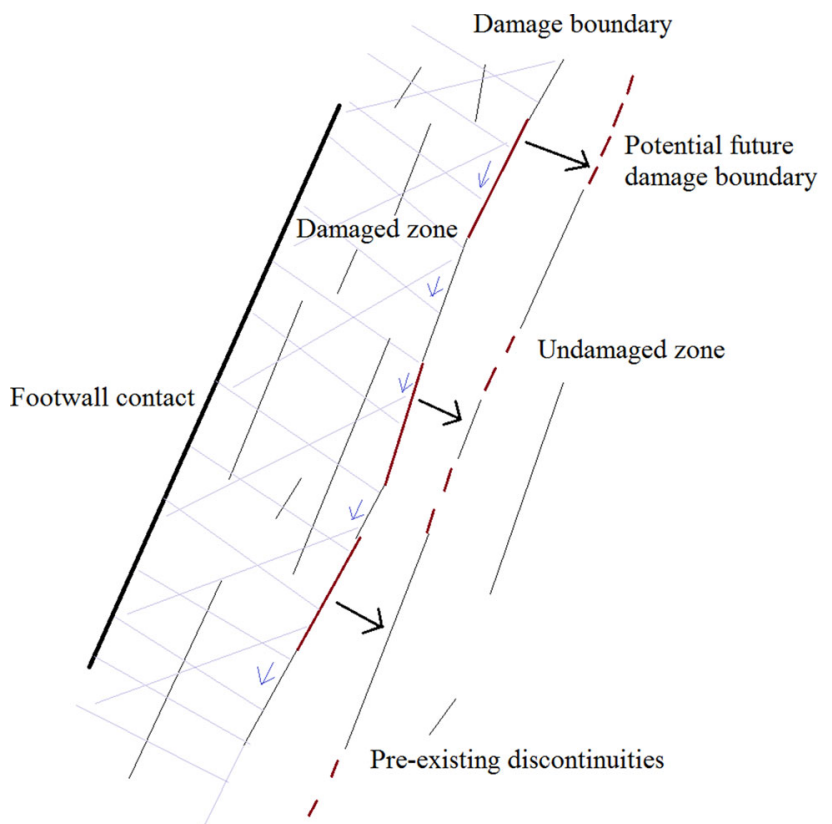

Fig. 14 Stepping concept for the damage boundary surface in the upper and middle parts of the footwall

mass property approach in favor of explicit joint modeling through, e.g., DFN or Voronoi tessellation may affect the indicated failure mode, especially with respect to the postulated step-path failure. The problem with such explicit modeling approaches is the availability of calibration data. In the case presented, the numerical models were calibrated with respect to the mapped damage and the inferred surface connecting the observations. It was shown by the review of earlier models that the assumed mechanical properties of the rock mass components varied significantly depending on the purpose of the model. Introducing additional parameters into the model, i.e., joint and fracture properties, would, in this case, only add to the uncertainties, as the calibration data would remain the same. In short, what was studied was not the explicit rock mass properties but the conceptual behavior of the entire system. It was, therefore, opted to keep the model simple and lucid by limiting the number of variable parameters. Future models within the project will, however, require higher levels of sophistication to more directly study the footwall-cave rock interaction and the possible influence from rock mass structures.

The numerical models and damage mapping campaign were combined to help explain the large-scale footwall fracturing in the Kiirunavaara mine. They are both integral parts, as each data set lacks in coverage and, thus, overlapping and co-analysis is essential for reliable conclusions. Especially, damage mapping is restricted to accessible stopes and that relatively large deformations are required before definitive observations can be made.

\section{Conclusions}

This paper has presented results from damage mapping and calibration of numerical models aiming to study the predominant failure mechanisms in the Kiirunavaara footwall. The combined analyses were used as the foundation in designing a large-scale measuring system to monitor rock mass displacements in the footwall. The numerical models have provided a plausible explanation of the evolution path of the large-scale fracturing outlined by the mapping data. Identification of underlying damage mechanisms did subsequently allow for the requirements of a monitoring 
system to be specified. The major conclusions of this work are:

- The propagation path of the large-scale footwall fracturing in the Kiirunavaara mine varies with depth. In the uppermost part of the footwall, the failure follows pre-existing structure sets. These sets are mobilized at deeper levels, allowing large-scale slip. At depth, the structure sets controlling the failures in the upper part are intersected by a step-path failure resembling curved shear failure through the rock mass. This step-path failure intersects the "footwall slope surface" inside the sublevel caving (SLC) zone.

- The step-path failure at deeper levels is indicated to be pre-conditioned by rock mass fracturing on and below the active excavation level. The failure surface develops as the rock mass becomes de-stressed due to heave or deformation into the SLC zone, allowing the preconditioned rock mass weaknesses to mobilize.

- A system monitoring a potential large-scale fracturing must be able to accommodate large concentrated shear movement at shallow levels and extensional deformation in combination with possible diffuse shear at deep levels.

By using the knowledge gained from this study, a preliminary monitoring system design has been proposed, from which a pilot profile is currently being installed.

Acknowledgments The authors acknowledge the funding and data access granted for this study by LKAB. Thanks are also due to the Centre of Mining and Metallurgy (CAMM) at Luleå University of Technology (LTU). The authors also acknowledge the on-site contributions during data collection by the LKAB research staff. Finally, the authors wish to thank Adjunct Professor Jonny Sjöberg at Itasca Consultants $\mathrm{AB}$ for the valuable comments on this paper.

Open Access This article is distributed under the terms of the Creative Commons Attribution 4.0 International License (http:// creativecommons.org/licenses/by/4.0/), which permits unrestricted use, distribution, and reproduction in any medium, provided you give appropriate credit to the original author(s) and the source, provide a link to the Creative Commons license, and indicate if changes were made.

\section{References}

Andersson UB (2009) Geologisk beskrivning ny huvudnivå-KUJ 1365 (in Swedish). LKAB: internal document 615167

Dahnér-Lindqvist C (1992) Liggväggstabiliteten i Kiirunavaara (in Swedish). Bergmekanikdagen, BeFo, Stockholm

Edelbro C, Sjöberg J, Malmgren L, Dahnér-Lindqvist C (2012) Prediction and follow-up of failure and fallouts in footwall drifts in the Kiirunavaara mine. Can Geotech J 49:546-559
Henry E (2000) Liggväggstabilitet med hänsyn till planering av en ny pumpvattenkedja. Slutrapport (in Swedish). LKAB: internal document 00-821

Henry E, Dahnér-Lindqvist C (2000) Footwall stability at the LKAB's Kiruna sublevel caving operation, Sweden. In: Proceedings of MassMin 2000, the Australasian Institute of Mining and Metallurgy, Brisbane, Australia, October/November 2000, pp 527-532

Hoek E, Bray JW (1981) Rock slope engineering. Institution of Mining and Metallurgy, London, $358 \mathrm{pp}$

Hoek E, Diederichs MS (2006) Empirical estimation of rock mass modulus. Int J Rock Mech Min Sci 43:203-215

Itasca Consulting Group (ICG) (2011) UDEC user's guide version 5. ICG, Minneapolis

Lupo JF (1996) Evaluation of deformations resulting from mass mining of an inclined orebody. Doctoral thesis, Colorado School of Mines, Golden, CO

Malmgren L, Nordlund E (2008) Interaction of shotcrete with rock and rock bolts-a numerical study. Int J Rock Mech Min Sci 45:538-553

Malmgren L, Sjöberg J (2006) Bergmekaniska analyser för ny huvudnivå KUJ (avv 1365) (in Swedish). LKAB: internal document 06-797

Mattsson H, Berglund J, Magnor B (2010) Strukturgeologisk modell över Kiruna gruvområde (in Swedish). LKAB: internal document $10-874$

Nilsson M, Saiang D, Nordlund E (2014) Fracturing in the footwall at the Kiirunavaara mine, Sweden. In: Proceedings of the 3rd international symposium on block and sublevel caving, Universidad de Chile, Santiago, Chile, June 2014, pp 63-71

Perman F, Sjöberg J (2011) Numerisk analys av brytningssekvenser i block 19 (in Swedish). LKAB: internal document 11-776

Sandström D (2003) Analysis of the virgin state of stress at the Kiirunavaara mine. Licentiate thesis 2003:02, Luleå University of Technology, Luleå, Sweden

Singh UK, Stephansson OJ, Herdocia A (1993) Simulation of progressive failure in hanging-wall and footwall for mining with sub-level caving. Trans Inst Min Metall A 102:A188-A194

Sitharam TG, Madhavi Latha G (2002) Simulation of excavations in jointed rock masses using a practical equivalent continuum approach. Int J Rock Mech Min Sci 39:517-525

Sjöberg J (1999) Analysis of large scale rock slopes. Doctoral thesis 1999:01, Luleå University of Technology, Luleå, Sweden

Sjöberg J, Lundman P, Nordlund E (2001) Analys och prognos av utfall i bergschakt, KUJ 1045. Slutrapport (in Swedish). LKAB: internal document 01-762

Stöckel B-M, Mäkitaavola K, Sjöberg J (2013) Hangingwall and footwall slope stability issues in sublevel caving. In: Proceedings of slope stability 2013, Australian Centre for Geomechanics, Brisbane, September 2013, pp 1045-1060

Svartsjaern M (2015) Predominant failure mechanisms at the Kiirunavaara mine footwall. Licentiate thesis, Luleå University of Technology, Luleå, Sweden

Villegas T, Nordlund E (2008) Numerical simulation of the hangingwall subsidence using PFC2D. In: Proceedings of MassMin 2008, the 5th international conference and exhibition on mass mining, Luleå University of Technology, Luleå, Sweden, June 2008, pp 907-916

Villegas B, Fernando T, Nordlund E (2013) Numerical analyses of the hangingwall failure due to sublevel caving: study case. Int J Min Miner Eng 4(3):201-223 